\title{
Corea del Sur: un importante socio para México
}

Melba E. Falck Reyes* Agustina Rodríguez Alegría*

0 orea del Sur es uno de los países de Asia Pacífico que ha tenido una de las tasas de crecimiento más notables después de la segunda guerra mundial. En sólo una generación la estructura de la economía cambió dramáticamente $y$, con ella, el nivel de ingreso de los coreanos. Después de ser una colonia japonesa (1910-1945), Corea resurgió como nación independiente enfrentando una guerra (1950-1953) que la separó del norte y que al mismo tiempo marcó su inserción especial en el exterior, la mayor parte del tiempo bajo el cobijo de Estados Unidos. El alto nivel de desarrollo de Corea del Sur y su elevado grado de apertura al exterior hacen de este país uno de los socios más importantes para México en Asia-Pacífico.

El propósito de este artículo es analizar la relación bilateral actual entre los dos países, destacando el potencial para profundizarla. En una primera sección se presenta, como marco de referencia general, el desenvolvimiento económico de Corea a partir de la segunda mitad del siglo pasado. En la segunda sección se analiza la relación bilateral entre los dos países desde tres ángulos: la complementariedad entre las dos economías, la relación comercial y la inversión extranjera directa.

\section{Evolución económica de Corea en la posguerra ${ }^{1}$}

Cuando los japoneses gobernaban el país, la mayor parte de la base industrial se estableció en la parte norte de la península; el sur era el proveedor de los bienes agrícolas a las ciudades. Así, Corea del Sur entró a la década de los cincuenta siendo un país rural atrasado. En el período de reconstrucción que siguió

* Profesoras investigadoras del Departamento de Estudios del Pacífico, de la Universidad de Guadalajara.

ORCID http://orcid.org/0000-0003-4926-0594 a la guerra de Corea, llegó la ayuda norteamericana bajo la forma de importaciones de alimentos; mientras la inversión en el país era financiada con capital extranjero. Durante ese período el gobierno siguió un modelo de desarrollo de sustitución de importaciones ( SI) apoyando a los conglomerados coreanos, los chaebol, respaldando las importaciones de insumos al facilitarles el acceso a las divisas y al crédito. La relación entre el gobierno y los chaebol se tornó cada vez más estrecha y tuvo una fuerte influencia sobre la política exterior en las décadas subsecuentes.

En los sesenta Corea inició su estrategia industrial orientada a las exportaciones apoyada en un estado autoritario intervencionista y proteccionista. La manufactura se desarrolló con base en la industria ligera mostrando tasas de crecimiento de 17 por ciento anual, mientras las exportaciones tenían un desempeño formidable con tasas de crecimiento del orden del 40 por ciento. Todo ello bajo una política de estímulo al crédito y subsidios a las exportaciones. Estas últimas impulsadas por una política gubernamental estricta con respecto al desempeño exportador de las empresas.

Al mismo tiempo que se promovía el sector exportador, se imponían tarifas y cuotas a las industrias internacionales competitivas. En 1967 Corea ingresó al Sistema General de Aranceles y Comercio (GATT, por sus siglas en inglés) con un status especial de nación subdesarrollada y utilizando la Cláusula de Balanza de Pagos (воР, por sus siglas in inglés) para proteger sus industrias. En esa década la economía coreana creció a tasas promedio de 8 por ciento anual, mientras el ingreso per cápita pasaba de 79 dólares en 1960 a 253 dólares después. Las exportaciones pasaron de uno por ciento del producto interno bruto (PIB) a 14 por ciento en el mismo período, mientras 
que la inversión duplicaba su participación relativa al pasar de 10 a 23 por ciento del PIв. ${ }^{2}$

La siguiente década atestiguó un cambió en la política industrial, orientada al desarrollo de la industria pesada y química, apoyada con incentivos fiscales y crediticios a industrias seleccionadas, como la del acero, la maquinaria, la química, la del hierro y la naviera. Con la crisis del petróleo de 1973, la industria coreana dependiente del petróleo, se vio seriamente afectada. $\mathrm{Al}$ mismo tiempo con las altas tasas de industrialización, los salarios crecían y la inflación se volvía un fenómeno crónico. Como consecuencia las exportaciones comenzaron a perder su margen de competitividad en los mercados internacionales.

En 1980 la contribución de la industria al PIB había crecido a 25 por ciento de un nivel de 9.7 por ciento en $1955 .{ }^{3}$ En la década de los setenta la economía coreana seguía creciendo a tasas aceleradas de 7.7 por ciento promedio anual. Las exportaciones llegaron a representar 34 por ciento del PIB a finales de la década, aunque su tasa de crecimiento promedio anual disminuyó de 44 por ciento, en la primera mitad de los setenta, a 28.8 en el segundo quinquenio de los setenta. La inflación en el período se mantuvo en los dos dígitos superiores a 15 por ciento promedio anual. La utilización anual de créditos externos aumento 2.6 veces en promedio, al pasar de 902 millones de dólares anuales en la primera mitad de la década a 2350 millones de dólares en la segunda mitad de los setenta.

A inicios de la década de los ochenta, Corea era ya una economía industrial moderna. El país se había urbanizado a tasas aceleradas, sobre todo alrededor de las regiones de Seúl y Pusan. Los trabajadores rurales eran atraídos por los elevados salarios urbanos. Los costos de compensación por hora para los trabajadores en la manufactura se duplicaron entre 1975 y 1980, al pasar de 5 por ciento de los costos laborales norteamericanos a 10 por ciento a finales de los ochenta. ${ }^{4}$

Los chaebol continuaban dominando la industria con una fuerte dependencia tanto de los fondos del sistema bancario nacional como de las fuentes externas. Esta alta tasa de dependencia tendría un serio impacto en la crisis de 1997. La segunda crisis del petróleo de 1979 afectó la estructura de costos de la economía y la inflación se hizo presente otra vez. Así, la primera mitad de los ochenta se caracterizó por una política monetaria y fiscal contraccionistas y por la aplicación de la de ingresos para controlar la inflación que había llegado a 28.8 por ciento en 1980.

Durante la segunda mitad de los ochenta, el gobierno comenzó a aplicar una política de liberalización, atemperando su intervención y reduciendo sus niveles proteccionistas. La mayoría de las restricciones cuantitativas sobre los bienes industriales fueron eliminadas y las tarifas fueron reducidas. Después de varias décadas de gobiernos militares, la democracia entró en la arena política en 1987 con una nueva constitución. El nuevo entorno político tendría un impacto en la forma en que los diferentes grupos de la sociedad podían expresar más libremente sus preocupaciones acerca la política económica.

En los ochenta la economía creció a un promedio anual de 8.8 por ciento y en 1995 el ingreso per cápita pasaba la barrera de los 10000 dólares. La inflación fue controlada promediando 6.4 por ciento en el período. La tasa de crecimiento promedio de la inversión 
en toda la década fue de 30 por ciento, mientras las exportaciones mostraban tasas de crecimiento menores. La utilización de crédito externo continuó complementando el ahorro interno para financiar la inversión. El fuerte crecimiento de la economía coreana en las décadas previas ahora atraía también la inversión extranjera. La inversión japonesa empezó a fluir a través de la normalización de las relaciones con Japón en 1972 y después, con la revaluación del yen en 1985, los capitales japoneses buscaron países con costos más bajos para trasladar parte de su producción.

Así, Corea entró a los noventa con un bien establecido status de nuevo país industrializado. El ingreso per cápita ascendió de 1420 dólares internacionales en 1960 a 9184 en 1990, sextuplicándose en sólo tres décadas. Más aún, los costos laborales pasaron de 25 por ciento de los costos norteamericanos en 1990 a 46 por ciento en $1996 .{ }^{5} \mathrm{El}$ grado de apertura de la economía era ya muy alto, las exportaciones representaban en 2000, 45 por ciento del PIB. Corea se había integrado fuertemente a la economía internacional.

Con esos indicadores Corea fue admitida en la oCDE en 1996. Dos años antes Corea había iniciado su reforma financiera. En 1996 los coreanos disfrutaban ya de un ingreso per cápita de 15625 dólares internacionales, 50 por ciento por arriba del nivel de 1990. Ese mismo año, Corea se vio seriamente afectada por el deterioro de sus términos de intercambio, cuando el precio de los microchips, uno de los renglones de exportación coreanos más importantes, se fue abajo. Las exportaciones en la segunda mitad de los noventa crecieron a tasas promedio de sólo 4 por ciento. Dado el fuerte nivel de endeudamiento de los chaebol y el débil sistema financiero, Corea se enfrentó a una severa crisis en 1997. Bajo el apoyo financiero del FMI, Corea se embarcó en una reestructuración comprehensiva de la economía, que abarcaba todos los sectores.

El objetivo de la reforma es transformar el modelo de desarrollo económico altamente intervencionista y autoritario por uno más orientado al mercado y basado en las preferencias de los consumidores, la democracia y el estado de derecho. De acuerdo con el presidente Kim Dae Jung, la "reforma debe comenzar con el gobierno", introduciendo una nueva disciplina de transparencia y principios de mercado en todo el aparato de toma de decisiones públicas. Así, en 1998 y 1999 se llevó a cabo una desregulación masiva y las regulaciones del gobierno fueron disminuidas en 50 por ciento. Las reformas ahora están dirigidas a una política regulatoria más pro-activa y comprehensiva y a la construcción de instituciones. El gobierno coreano también ha reducido las barreras al comercio y liberalizado la inversión extranjera para atraer los capitales. Se ha incrementado el ritmo de privatización de las empresas y se ha establecido un nuevo régimen regulatorio e institucional en el sector financiero. El llamado "problema de los chaebol" está siendo enfrentado con una fuerte reestructuración. Los sectores de electricidad y telecomunicaciones están siendo paulatinamente reformados también. ${ }^{6}$

El modelo de desarrollo que Corea adoptó, orientado hacia afuera con la intervención de un estado autoritario, alcanzó su objetivo "utilizando crédito externo, el apoyo militar de Estados Unidos y la explotación de los trabajadores coreanos", como ha sido señalado por Castells. ${ }^{7}$ La introducción de la democracia en el país a partir de 1987, el fortalecimiento de los gobiernos civiles desde 1993 y la crisis económica de 1997 han inducido cambios importantes en el modelo donde la relación entre el Estado, el mercado y los ciudadanos se ha modificado de manera sustancial. En este contexto de mayor apertura económica y política es que se han profundizado las relaciones económicas entre Corea y México.

\section{La complementariedad económica}

Por el tamaño de sus economías, ambos países son muy similares. México es la décima economía del mundo y Corea la décimo tercera. ${ }^{8}$ Sin embargo, hay diferencias importantes entre los dos países. En primer lugar, por el nivel de ingreso que perciben sus habitantes, Corea 
se sitúa entre el grupo de países con alto grado de desarrollo en el APEC, mientras que México se ubica entre los países de desarrollo intermedio. Esta situación no fue siempre así, a principios de la década de los cincuenta el ingreso de los coreanos estaba muy por debajo del de los mexicanos. ${ }^{9}$ Actualmente los coreanos perciben un ingreso de 15060 dólares internacionales, 1.8 veces por arriba del correspondiente a los mexicanos (cuadro 1 ). Corea también tiene una mejor distribución del ingreso que México. El ingreso del 20 por ciento de las familias de más altos ingresos en Corea es 4.7 veces superior al del 20 por cien-

Cuadro 1

Mexico y Corea del Sur: principales indicadores económicos, 2003

\begin{tabular}{|c|c|c|}
\hline Indicadores & Corea del Sur & México \\
\hline 1. Territorio, miles de $\mathrm{km}^{2}$ & 98.7 & $1,958.0$ \\
\hline 2. Población, miles & $47,900.0$ & $102,300.0$ \\
\hline Población urbana en el total (\%) & 80.0 & 75.0 \\
\hline Densidad de población $/ \mathrm{km}^{2}$ & 476.0 & 49.0 \\
\hline Esperanza de vida, años & 73.9 & 73.6 \\
\hline Mortalidad infantil por mil nacidos vivos & 5.0 & 24.0 \\
\hline Mujer en la fuerza de trabajo (\%) & 41.6 & 33.5 \\
\hline Población mayor de 65 años (\%) & 38.0 & 5.0 \\
\hline Promedio escolar (número años)* & 10.8 & 7.2 \\
\hline \multicolumn{3}{|l|}{ 3. Economía } \\
\hline Ingreso Nacional Bruto (GNI), miles de dólares & $603,300.0$ & $626,100.0$ \\
\hline GNI per cápita, dólares & $9,460.0$ & $6,230.0$ \\
\hline GNI en dólares internacionales (PPP) & $15,060.0$ & $8,240.0$ \\
\hline Tasa de crecimiento promedio, 1993-2003 (\%) & 4.1 & 1.7 \\
\hline \multicolumn{3}{|l|}{ Composición del PIB (\%) } \\
\hline Agricultura & 3.2 & 4.0 \\
\hline Industria & 34.6 & 26.4 \\
\hline Servicios & 62.2 & 69.6 \\
\hline Fuerza de trabajo ${ }^{\star *}$ miles & $23,981.0$ & $40,047.0$ \\
\hline en agricultura $(\%)^{\star \star}$ & 9.9 & 21.3 \\
\hline Inversión en PIB (\%) & 29.4 & 19.8 \\
\hline Ahorro bruto interno en el PIB (\%) & 31.9 & 18.2 \\
\hline Tasa promedio anual de inflación, 1995-2000 (\%) & 5.0 & 18.9 \\
\hline \multicolumn{3}{|l|}{ 4. Sector externo } \\
\hline$\overline{\text { Exportaciones (FOB), miles de dólares }}$ & $193,817.0$ & $164,240.0$ \\
\hline Manufactura en el total $(\%)^{*}$ & 91.0 & 85.0 \\
\hline Exportaciones de bienes y servicios en el PIB (\%)* & 38.2 & 28.4 \\
\hline Importaciones, miles de dólares & $178,827.0$ & $169,634.0$ \\
\hline Importaciones de bienes y servicios en el PIB $(\%)^{*}$ & 35.6 & 30.1 \\
\hline Deuda externa (millones de dólares) & $110,109.0$ & $158,290.0$ \\
\hline Como porcentaje del PIB & $\ldots$ & 22.6 \\
\hline Servicio de la deuda/exportaciones & $\ldots$ & 20.0 \\
\hline Arribo de turistas al año (miles de personas) (\%) & $5,322.0$ & $19,811.0$ \\
\hline Salida de turistas al año (miles de personas) & $5,508.0$ & $11,081.0$ \\
\hline \multicolumn{3}{|l|}{ 5. Otros indicadores de nivel de vida } \\
\hline Consumo percápita de electricidad, kwh & $5,607.0$ & $1,655.0$ \\
\hline Líneas telefónicas y telefónos móviles por 1000 personas & 486.0 & 137.0 \\
\hline Ingreso del $20 \%$ más rico $(\%)$ & 37.5 & 57.6 \\
\hline Ingreso del $20 \%$ más pobre (\%) & 7.9 & 3.4 \\
\hline
\end{tabular}


to de los hogares más pobres; en México esta diferencia es de 16.9 veces. Un factor clave en el ascenso de la clase media de Corea ha sido la educación. El promedio de escolaridad en Corea es de once años, que contrasta con siete años para México.

El fuerte crecimiento de la economía coreana en las últimas tres décadas impulsó los salarios al alza. Así, el costo promedio del trabajador coreano en la manufactura, en el período 1995 a 1999, fue de 10743 dólares al año, 30 por ciento por arriba del costo promedio del trabajador mexicano.

La estructura productiva de los dos países muestra también diferencias. Aunque la participación del sector agrícola en ambas economías es similar (4 por ciento), el sector industrial tiene un peso relativo mucho más importante en Corea que el que tiene en México, 35 y 26 por ciento, respectivamente; mientras el sector servicios es más relevante en México (67 por ciento) que en Corea (64 por ciento). Corea, por su parte, emplea 10 por ciento de su población activa en el sector agrícola, mientras en México este sector ab- sorbe cerca de una quinta parte de la fuerza de trabajo.

Corea impulsó mucho antes que México el modelo de crecimiento orientado a las exportaciones y ello se refleja tanto en el nivel de comercio exterior como en el mayor grado de apertura de la economía coreana. Para ese país, tanto las exportaciones como las importaciones representan más de 35 por ciento del PIB, mientras en México éstas participan en una menor proporción, 30 por ciento cada una. Dada la escasez relativa de recursos naturales, Corea ha promovido las exportaciones como una vía para adquirir los insumos y materiales necesarios para el desarrollo de su industria.

A lo largo de la década de los noventa, Corea mantuvo un nivel creciente de comercio exterior (exportaciones más importaciones), con un promedio de 245 mil millones de dólares, 16 por ciento superior al nivel promedio de México (cuadro 2). Sin embargo, dadas las mayores tasas de crecimiento del comercio exterior de México durante ese período, la brecha se fue reduciendo hacia fina-

Cuadro 2

Corea y México: evolución de la balanza comercial, 1990-2003 (millones de dólares)

\begin{tabular}{|c|c|c|c|c|c|c|c|c|}
\hline Año & Exportaciones & $\begin{array}{c}\text { Corea } \\
\text { Importaciones }\end{array}$ & Saldo & Comercio & Exportaciones & $\begin{array}{c}\text { México } \\
\text { Importaciones }\end{array}$ & Saldo & Comercio \\
\hline 1990 & 65,015 & 69,843 & $-4,828$ & 134,858 & 40,710 & 41,593 & -883 & 82,303 \\
\hline 1991 & 71,870 & 81,524 & $-9,654$ & 153,394 & 42,687 & 49,966 & $-7,279$ & 92,653 \\
\hline 1992 & 76,631 & 81,775 & $-5,144$ & 158,406 & 46,195 & 62,129 & $-15,934$ & 108,324 \\
\hline 1993 & 82,235 & 83,800 & $-1,565$ & 166,035 & 51,886 & 65,366 & $-13,480$ & 117,252 \\
\hline 1994 & 96,013 & 102,348 & $-6,335$ & 198,361 & 60,882 & 79,346 & $-18,464$ & 140,228 \\
\hline 1995 & 125,058 & 135,118 & $-10,060$ & 260,176 & 79,542 & 72,453 & 7,089 & 151,995 \\
\hline 1996 & 129,715 & 150,339 & $-20,624$ & 280,054 & 95,999 & 89,469 & 6,530 & 185,468 \\
\hline 1997 & 136,164 & 144,615 & $-8,451$ & 280,779 & 110,431 & 109,807 & 624 & 220,238 \\
\hline 1998 & 132,313 & 93,281 & 39,032 & 225,594 & 117,459 & 125,373 & $-7,914$ & 242,832 \\
\hline 1999 & 143,686 & 119,752 & 23,934 & 263,438 & 136,391 & 141,974 & $-5,583$ & 278,365 \\
\hline 2000 & 172,268 & 160,481 & 11,787 & 332,749 & 166,455 & 174,457 & $-8,002$ & 340,912 \\
\hline 2001 & 150,439 & 141,097 & 9,342 & 291,536 & 158,443 & 168,396 & $-9,953$ & 326,839 \\
\hline 2002 & 162,470 & 152,126 & 10,344 & 314,596 & 160,763 & 168,679 & $-7,916$ & 329,442 \\
\hline 2003 & 193,817 & 178,826 & 14,991 & 372,643 & 164,860 & 170,551 & $-5,691$ & 335,411 \\
\hline Promedio anual & 124,121 & 121,066 & 3,055 & 245,187 & 102,336 & 108,540 & $-6,204$ & 210,876 \\
\hline Crecimiento & 8.8 & 7.5 & -209.1 & 8.1 & 11.4 & 11.5 & 15.4 & 11.4 \\
\hline
\end{tabular}

Fuente: Banco de México, informes económicos varios números; National Statistical Office, Korea Statistical

Yearbook 2004, Republic of Korea; International Monetary Fund, International Financial Statistics, mayo de 2002. 
les de los noventa. La severa crisis que sufrió Corea en 1997 provocó que las importaciones retomaran los niveles de 1996 hasta 2000.

Para ambas naciones las exportaciones de manufacturas constituyen alrededor de 90 por ciento del total; no obstante, en el caso coreano éstas tienen un alto contenido de valor agregado. Reflejando la escasa dotación de recursos naturales en Corea, las importaciones de combustibles y materias primas representan alrededor de una tercera parte del total de importaciones; mientras que los alimentos constituyen alrededor de 5 por ciento del total. ${ }^{10}$ En el caso de México, el 90 por ciento de las importaciones están constituidas por bienes intermedios y de capital. ${ }^{11}$

Al igual que en Japón, las exportaciones de manufacturas para Corea son vitales para relajar la restricción impuesta por la escasa dotación de recursos naturales y mantener en funcionamiento a la industria. Sin embargo, a diferencia de Japón, Corea depende en mayor medida de la demanda externa de sus productos y, por lo tanto, su inserción en los mercados internacionales está orientada a mantener y mejorar el acceso a dichos mercados. Esa fue la razón para que, no obstante la presión interna por mantener cerrado el mercado agrícola, Corea decidió en 1994 otorgar acceso cuantitativo al mercado del arroz. No era conveniente a los intereses del país, sacrificar el eficiente sector exportador manufacturero, para proteger una agricultura poco competitiva e ineficiente en el uso de los factores.

A diferencia de México, Corea tiene un comercio mucho más diversificado. Por regiones, su principal mercado de exportaciones es Asia (33 por ciento del total) y en esa zona destacan China (20 por ciento) y Japón ( 9 por ciento). Norteamérica es la segunda región en importancia, hacia ella Corea destina una quinta parte de sus exportaciones, siendo Estados Unidos su principal socio comercial (18.2 por ciento). Europa ocupa el tercer lugar con 14 por ciento de las exportaciones coreanas. En lo que respecta a las importaciones, también los principales proveedores de Corea están en

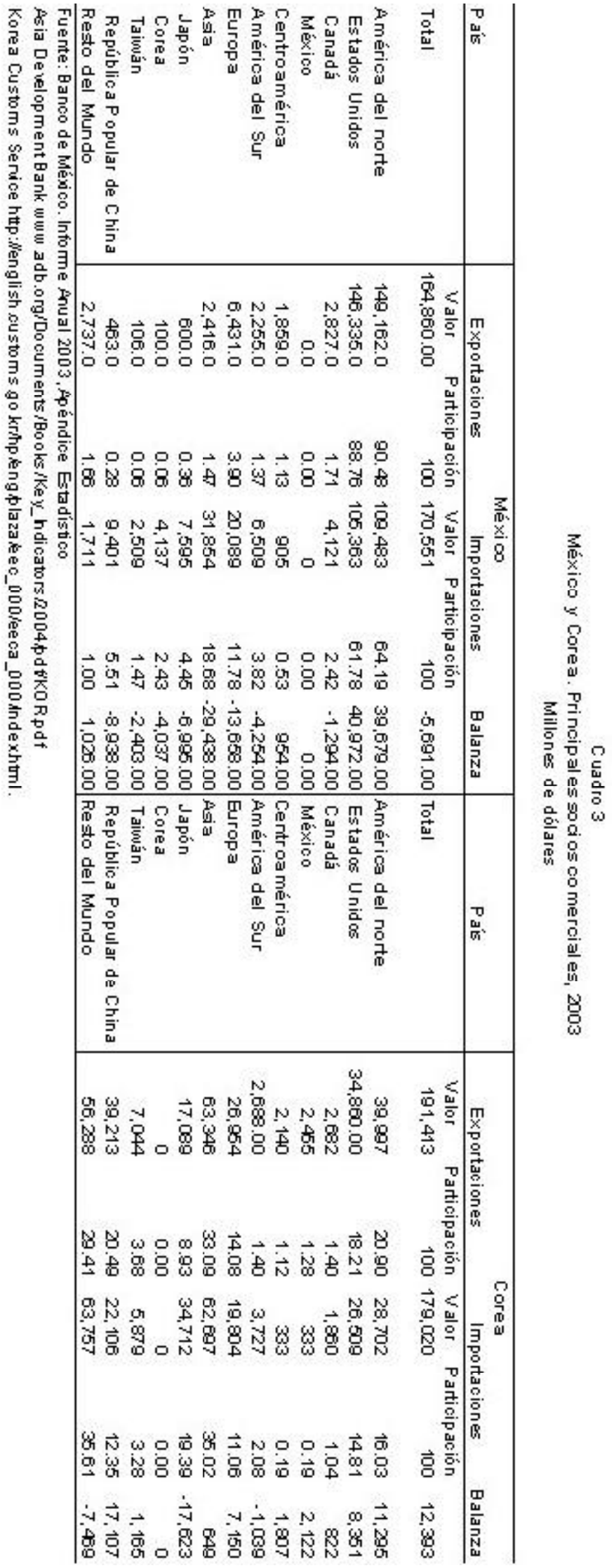


Asia; Japón participa con 19 por ciento de las importaciones y con ese país Corea mantiene un saldo comercial negativo, reflejando el comercio intrafirmas entre los dos países. América del Norte es el segundo proveedor más importante de Corea y, en esa región, Estados Unidos participa con 15 por ciento. Europa se encuentra en tercer lugar, con una participación de 11 por ciento (cuadro 3). México, por su parte, mantiene una fuerte dependencia del mercado de Estados Unidos (90\% en exportaciones y 64 por ciento en importaciones), la cual se ha acentuado a partir del Tratado de Libre Comercio (TLCAN).

Por el lado de las exportaciones México destina a Asia únicamente 1.5 por ciento del total. Con respecto a las importaciones la dependencia de Asia es mucho mayor y se ha ido incrementando a partir de los noventa. Esta región provee ya el 19 por ciento de las compras de México en el exterior; siendo los tres principales proveedores China, Japón y Corea, que participan con $5.5,4.5$ y 2.4 , respectivamente. Cabe mencionar que, por regiones, México mantiene déficits comerciales con América Latina, Europa y Asia, y entre ellas, el mayor déficit lo tiene con Asia. Este último es compensado en buena medida con el supe- rávit generado con Estados Unidos y Canadá en el TLCAN. No obstante lo anterior, es importante señalar que la inversión extranjera directa de las empresas japonesas y coreanas establecidas en México, se concentra en empresas cuya principal actividad es la exportación, contribuyendo de esa manera a las exportaciones que México destina hacia otras regiones, especialmente a América del Norte. Por ejemplo, de las 100 principales empresas exportadoras mexicanas, trece japonesas exportan alrededor de 8 mil millones de dólares a Estados Unidos. Estas estadísticas no se reflejan en el déficit comercial antes mencionado.

Por la dotación de factores, los dos países difieren marcadamente. Con un territorio de 120 mil kilómetros cuadrados, la porción de la península que ocupa Corea del Sur representa 6 por ciento del territorio mexicano. Más aún, con 48 millones de habitantes y 63 por ciento de su superficie cubierta de bosques, Corea tiene una elevada densidad poblacional, muy superior a la de México. La tierra cultivable en Corea está constituida por 1.9 millones de hectáreas, la cual representa 10 por ciento de la disponible en México (20 millones de hectáreas).

Cuadro 4

México: comercio con Corea del Sur, 1995-2003

(miles de dólares)

\begin{tabular}{crrrr}
\hline Año & $\begin{array}{c}\text { Exportaciones } \\
\text { Fob }\end{array}$ & $\begin{array}{c}\text { Importaciones } \\
\text { Fob }\end{array}$ & $\begin{array}{c}\text { Balanza } \\
\text { comercial }\end{array}$ & $\begin{array}{c}\text { Comercio } \\
\text { total }\end{array}$ \\
\hline 1995 & 307,000 & 974,172 & $-667,172$ & $1,281,172$ \\
1996 & 408,000 & $1,177,441$ & $-769,441$ & $1,585,441$ \\
1997 & 344,000 & $1,831,023$ & $-1,487,023$ & $2,175,023$ \\
1998 & 191,000 & $1,951,288$ & $-1,760,288$ & $2,142,288$ \\
1999 & 292,000 & $2,963,984$ & $-2,671,984$ & $3,255,984$ \\
2000 & 378,000 & $3,854,800$ & $-3,476,800$ & $4,232,800$ \\
2001 & 267,000 & $3,631,600$ & $-3,364,600$ & $3,898,600$ \\
2002 & 295,000 & $3,947,600$ & $-3,652,600$ & $4,242,600$ \\
2003 & 334,000 & $4,112,885$ & $-3,778,885$ & $4,446,885$ \\
& & & & \\
Nivel promedio período & 312,889 & $2,716,088$ & $-2,403,199$ & $3,028,977$ \\
Crecimiento promedio (\%) & 1.1 & 19.7 & 24.2 & 16.8 \\
\hline
\end{tabular}

Fuente: para importaciones, INEGI, Banco de Información Económica, http://www.inegi.gob.mx. Secretaría de Economía, http://www.economia.gob.mx. Para exportaciones, Korea International Trade Association (KITA). 
Debido a las elevadas tasas de crecimiento experimentadas por Corea, sobre todo en el sector manufacturero, la demanda por mano de obra se incrementó rápidamente y en la última década ello ha llevado a una escasez relativa de la fuerza de trabajo. Así, los dos factores relativamente más escasos para ese país son la tierra y la mano de obra, lo cual contrasta con el caso de México.

Tanto por las diferencias en el nivel de desarrollo, en la estructura productiva y en la dotación de recursos, las economías mexicana y coreana tienden a ser más complementarias que competitivas. En el sector agrícola, la complementariedad tiende a ser más marcada.

\section{La relación bilateral entre Corea y México}

Aunque las relaciones oficiales entre México y Corea iniciaron en los sesenta, es hasta tres décadas más tarde cuando esta relación se intensificó. De los trece acuerdos sobre diferentes formas de cooperación firmados por los dos países entre 1966 y 2000 , ocho se formalizaron en la década de los noventa. ${ }^{12}$ Enjunio de 2001, con motivo de la visita del presidente Fox a Corea, se estableció la Comisión México-Corea para el Siglo XXI, como un foro privado de consulta para profundizar la cooperación entre los dos países. Esta comisión se ha reunido ya en tres ocasiones. La tercera se realizó en Seúl, en mayo de 2004, y se establecieron cuatro áreas de cooperación: relaciones internacionales, economía, industria y cultura, educación y deportes. ${ }^{13}$ Así, México se ha convertido en el principal socio de comercio e inversión de Corea en Latinoamérica y el Caribe. En 2005 se cumple el centenario de la primera inmigración de coreanos a Yucatán, que llegaron a México para trabajar en las haciendas yucatecas y luego se dispersaron por todo el país. ${ }^{14}$

A partir de la segunda mitad de los noventa, el comercio total (exportaciones más importaciones) entre Corea y México pasó de 1.3 mil millones de dólares en 1995 a $4.4 \mathrm{mil}$ millones de dólares en 2003 , lo que significa que en promedio el crecimiento anual de la relación comercial bilateral fue de 17 por ciento. En términos de importancia relativa, Corea es el sexto socio comercial de México, mientras que México representa para Corea el vigésimo sexto socio comercial.

El mayor crecimiento en la relación bilateral comercial se observó en las importaciones que México realiza de ese país asiático, las cuales mostraron una tasa de crecimiento promedio anual de 19.7 por ciento. Mientras tanto, las exportaciones mexicanas a Corea apenas crecieron 1.1 por ciento promedio anual en el período (cuadro 4). Así, en 2003 México exportó a Corea un total de 334 millones de dólares e importó de ese país 4.1 mil millones de dólares. ${ }^{15}$ Lo anterior se refleja en un creciente déficit para México a lo largo de todo el período. Este resultado en la balanza comercial es consecuencia en parte del comercio intrafirma entre las multinacionales coreanas establecidas en México y sus proveedores en Corea. Resalta además que Corea se ha interesado en México como una plataforma para penetrar el mercado norteamericano, ${ }^{16}$ y ha sabido aprovechar la mayor apertura del mercado mexicano desde mediados de los ochenta, mientras que México no ha desarrollado una estrategia de largo plazo de penetración de ese mercado asiático. ${ }^{17}$ El total de las exportaciones mexicanas a Corea representa apenas el 0.20 por ciento del total de las ventas de México al exterior, lo cual constituye un indicador del potencial de diversificación en ese mercado. Mientras tanto, las importaciones representan 2.4 por ciento del total de las compras que realiza México en el exterior.

Por principales productos, las exportaciones mexicanas que han mostrado una tendencia creciente entre 2001 y 2003 incluyen productos fotográficos, partes de telefonía y de automóviles, lámparas y válvulas electrónicas e hilados. Entre los diez principales productos exportados también destacan algunos bienes alimenticios como moluscos, cerveza y confituras. En total este grupo de productos representó en 2003 dos terceras partes de las exportaciones mexicanas a Corea (cuadro 5). 
Por el lado de las importaciones, la mitad está constituida por las partes y componentes para equipo de oficina, de televisión y electrónicos.

\section{El comercio agrícola}

Aunque México y Corea se encuentran entre el grupo de importadores netos agrícolas en el APEC, el comercio agrícola de ambos presenta una estructura diferente. Durante el período 1994 a 2000, Corea mantuvo un saldo negativo en su comercio agrícola, con un promedio anual de 7 mil millones de dólares, resultado de un nivel promedio de exportaciones de 1.6 mil millones de dólares y de importaciones de 8.6 mil millones. Las exportaciones agrícolas coreanas representaron apenas un 18.6 por ciento del total de importaciones. México, por su parte, mantuvo un saldo deficitario de 1.6 mil millones de dólares producto de un nivel de exportaciones de 6.2 mil millones y de 7.8 mil millones de importaciones. En este caso, las exportaciones agrícolas representaron 80 por ciento del total de importaciones.
Tanto por la escasez de recursos como por las presiones por el lado de la demanda al aumentar el nivel de ingreso de sus habitantes, las importaciones agroalimentarias de Corea han tendido ha aumentar rápidamente: tiene actualmente el séptimo lugar como mayor importador de alimentos del mundo. ${ }^{18}$ Entre 1995 y 2002, Corea importó 9 mil millones de dólares anuales en alimentos. Así, Corea presenta en general niveles más bajos de autosuficiencia alimentaria comparados a los que tiene México. Por grupos de productos, los coreanos importan alrededor de 70 por ciento de sus necesidades de consumo en cereales. En maíz y trigo son altamente dependientes del exterior, ya que el fuerte crecimiento del sector pecuario ha presionado al alza las importaciones de cereales forrajeros. México mantiene niveles de autosuficiencia alimentaria superiores a los de Corea. En oleaginosas la dependencia de ambos países es muy alta: 80 por ciento para México y 90 por ciento para Corea. En cárnicos, los dos países complementan el consumo con las importaciones, aunque esta dependencia es mayor para Corea (30 por ciento). En lo que

Cuadro 5

México: principales productos de exportación a Corea del Sur, 2001-2003

\begin{tabular}{lrrr}
\hline & 2001 & 2002 & \multicolumn{1}{c}{2003} \\
\hline Exportaciones totales (millones de dólares) & 158443 & 160763 & 165355 \\
Exportaciones a Corea del Sur, respecto al total nacional (\%) & 0.17 & 0.18 & 0.20 \\
& & & \\
Corea del Sur (total \%) & 100 & 100 & 100 \\
& & & \\
Diez principales productos & 10.49 & 21.8 & 66.04 \\
Fotográficos o cinematográficos & & & \\
Hilados de filamentos artificiales & 0 & 0.01 & 16.65 \\
Moluscos & 0.4 & 6.87 & 10.1 \\
Partes de telefonía & 1.97 & 3.91 & 8.02 \\
Lámparas, tubos y válvulas electrónicos & 0.28 & 0.58 & 7.2 \\
Ácidos nucleicos y sus sales & 0.63 & 0.05 & 7.07 \\
Cerveza de malta & 0 & 1.26 & 4.44 \\
Confituras, jaleas y mermeladas, purés y pastas & 0.79 & 1.72 & 3.7 \\
Partes y accesorios de vehículos, automóviles & 0 & 0 & 3.34 \\
Antibióticos & 6.35 & 6.8 & 2.81 \\
& 0.07 & 0.6 & 2.71 \\
Otros & & & \\
\hline
\end{tabular}

Fuente: Bancomext, World Trade Atlas, 2003. 
respecta a vegetales y a frutas, México mantiene excedentes para exportación y en ambos grupos de productos su autosuficiencia es mucho mayor a la de Corea. Esta última importa 20 por ciento de sus necesidades de consumo de frutas. Así, la mayor ventaja para México está en aquellos productos más intensivos en el uso de mano de obra, como frutas y vegetales.

En cuanto al comercio agrícola entre ambos países, las exportaciones mexicanas de productos agroalimentarios a Corea se multiplicaron por siete en el período 1993 a 2001, al pasar de 4 millones de dólares en 1993 a 28 millones de dólares en 2001. Ello significa que las exportaciones agrícolas mostraron una tasa de crecimiento muy superior ( 27 por ciento) a la del promedio de las exportaciones (5.9 por ciento). En el total de exportaciones de México a Corea, las agroalimentarias representaron en el período 17.9 por ciento del total. ${ }^{19}$

En el total de exportaciones agroalimentarias de México al mundo, la participación de Corea es marginal. No obstante, cabe señalar que las exportaciones agroalimentarias a ese país aumentaron su parti- cipación de 0.10 por ciento en 1993 a 0.35 por ciento en 2001, ya que la tasa de crecimiento de las exportaciones a Corea fue tres veces superior a la de las exportaciones totales.

Por otra parte, la participación mexicana en el total de importaciones agroalimentarias de Corea, también mostró una tendencia ascendente, al pasar de 0.06 por ciento en 1993 a 0.34 por ciento en 2001 . No obstante, esta participación es todavía marginal y considerando los elevados niveles de importación de alimentos de Corea, este mercado ofrece un amplio potencial de desarrollo para México. Actualmente, los mayores proveedores de productos agroalimentarios para Corea son Estados Unidos, Australia y, recientemente, China. ${ }^{20}$

México exporta alrededor de 36 productos agroalimentarios a Corea. De éstos, cuatro grupos de productos muestran una presencia constante en el período 1993 a 2001: pescados, sal, cueros y pieles y café. En tanto, seis productos tienen una presencia importante a partir de 1996: bebidas alcohólicas, algodón, preparaciones de carne, aceites esenciales, frutos comestibles, azúcares y ca-

Cuadro 6

México: principales productos de importación de Corea del Sur, 2001-2003

\begin{tabular}{lrrr}
\hline & 2001 & 2002 & \multicolumn{1}{c}{2003} \\
\hline Importaciones totales (millones de dólares) & 168396 & 168679 & 170958 \\
Importaciones de Corea del Sur, respecto al total nacional & 2.1 & 2.3 & 2.4 \\
Corea del Sur (total \%) & 100.00 & 100.00 & 100.00 \\
Diez principales productos & 52.31 & 53.95 & 57.08 \\
Partes y accesorios para máquinas y aparatos de oficina & 5.62 & 14.49 & 20.81 \\
Partes para televisión o radiodifusión & 2.31 & 4.48 & 9.87 \\
Lámparas, tubos y válvulas eléctronicos & 12.01 & 8.19 & 7.28 \\
Circuitos integrados y microestructuras electrónicos & 8.72 & 10.54 & 5.44 \\
Coches de turismo y demás vehículos, automóviles & 3.6 & 2.61 & 2.81 \\
Máquinas automáticas para el procesamiento de datos & 8.75 & 4.4 & 2.65 \\
Aparatos emisores de radiotelefonía y radiotelegrafía & 3.54 & 3.2 & 2.22 \\
Ampollas y envolturas tubulares & 2.13 & 1.93 & 2.04 \\
Tejidos de hilados de filamentos sintéticos & 4.48 & 2.49 & 2.01 \\
Circuitos impresos & 1.15 & 1.62 & 1.95 \\
Otros & 47.69 & 46.05 & 42.92 \\
\hline
\end{tabular}

Fuente: Bancomext, World Trade Atlas, 2003. 
cao. El resto de los bienes muestra una tendencia variable. Por la participación en el total destacan cinco grupos de productos: pescados, sal, bebidas alcohólicas, algodón y aceites, con una participación en conjunto en 2001 de 87 por ciento.

En conclusión, las importaciones agroalimentarias de Corea han mostrado un crecimiento sostenido en la última década, convirtiendo a este país en uno de los mayores importadores netos de alimentos del mundo. Este fuerte crecimiento de las importaciones se ha visto impulsado tanto por el mayor nivel de ingreso de los coreanos y el consecuente cambio en la dieta alimenticia como por la mayor liberalización del sector, sobre todo a partir de 1994, con la conclusión de la Ronda de Uruguay. En la misma década, Corea y México han incrementado sustancialmente su relación bilateral, la cual ha mostrado un saldo crónico deficitario para México. El nivel de exportaciones de México a ese país se ha mantenido muy bajo. Una oportunidad para incrementarlo está en las exportaciones agroalimentarias dado el grado de complementariedad de las dos economías en este sector.

\section{La inversión coreana en México}

La inversión coreana en México se ha intensificado también a partir de los noventa. Para profundizar aún más la relación, el 14 de noviembre de 2000 los dos países firmaron el "Acuerdo entre el gobierno de los Estados Unidos Mexicanos y el gobierno de la República de Corea para la promoción y protección recíproca de inversiones". Bajo este acuerdo, cada país se compromete a promover y crear condiciones para que los inversionistas de los dos países realicen inversiones en su territorio, además de proveer un trato justo y equitativo y plena seguridad a la inversión.

De 1994 a 2003 la inversión extranjera directa (IED) de Corea en México acumuló un monto de 646 millones de dólares, lo que representa 0.5 por ciento del total de la IED que México captó en esos nueve años y 6.4 por ciento de la IED procedente de la Cuenca del Pací-

Cuadro 7

Inversión extranjera directa de Corea del Sur en México (miles de dólares)

\begin{tabular}{|c|c|c|c|c|c|c|}
\hline \multirow[b]{2}{*}{ Año } & \multicolumn{3}{|c|}{ Flujos $^{1 /}$} & \multicolumn{3}{|c|}{ Acumulado $^{2 /}$} \\
\hline & $\begin{array}{l}\text { IED de } \\
\text { Corea }\end{array}$ & $\begin{array}{c}\text { IED } \\
\text { del mundo }\end{array}$ & $\begin{array}{c}\text { Part. } \\
\%\end{array}$ & $\begin{array}{l}\text { IED de } \\
\text { Corea }\end{array}$ & $\begin{array}{c}\text { IED } \\
\text { del mundo }\end{array}$ & $\begin{array}{l}\text { Part. } \\
\%\end{array}$ \\
\hline 1994 & 15,065 & $10,659,162$ & 0.1 & 15,065 & $10,659,162$ & 0.1 \\
\hline 1995 & 103,754 & $8,332,851$ & 1.2 & 118,818 & $18,992,014$ & 0.6 \\
\hline 1996 & 85,836 & $7,748,677$ & 1.1 & 204,654 & $26,740,690$ & 0.8 \\
\hline 1997 & 199,169 & $12,192,620$ & 1.6 & 403,823 & $38,933,311$ & 1.0 \\
\hline 1998 & 52,576 & $8,289,173$ & 0.6 & 456,398 & $47,222,483$ & 1.0 \\
\hline 1999 & 46,180 & $13,205,507$ & 0.3 & 502,578 & $60,427,990$ & 0.8 \\
\hline 2000 & 29,763 & $16,585,706$ & 0.2 & 532,341 & $77,013,695$ & 0.7 \\
\hline 2001 & 43,860 & $26,775,686$ & 0.2 & 576,201 & $103,789,382$ & 0.6 \\
\hline 2002 & 30,614 & $13,628,161$ & 0.2 & 606,815 & $117,417,543$ & 0.5 \\
\hline 2003 & 39,516 & $9,738,458$ & 0.4 & 646,331 & $127,156,001$ & 0.5 \\
\hline Promedio & 64,633 & $12,715,600$ & 0.6 & 406,302 & $62,835,227$ & 0.7 \\
\hline
\end{tabular}

1/ Para 2002, 2003 y 2004 no incluye la estimación de la IED realizada que aún no ha sido notificada al RNIE.

2/ Para 1994-1998 la inversión extranjera directa (IED) se integra con los montos notificados al Registro Nacional de Inversiones Extranjeras (RNIE), más las importaciones de activo fijo realizadas por sociedades maquiladoras. A partir de 1999 se incluyen además los conceptos de nuevas inversiones, reinversión de utilidades y cuentas entre compañías, que se han notificado al RNIE. Cabe mencionar que esta información no reporta toda la inversión notificada por inversionistas coreanos, debido a que no se incluyen las inversiones que realizan las empresas de Corea a través de sus filiales en otros países, pues el país de la inversión se clasifica con base en la nacionalidad del inversionista extranjero y no respecto del origen primario de los recursos.

Fuente: Secretaría de Economía. Dirección General de Inversión Extranjera. Consultar en: www.economía-snci-gob.mx. 
fico (cuadros 7 y 8); en esa región Corea se ubica en el tercer lugar en importancia, antecedida por Japón y Singapur. ${ }^{21}$ Dos terceras partes de la inversión coreana se concentran en el sector manufacturero, sobre todo en fabricación o ensamble de equipo electrónico y aparatos domésticos (33 por ciento), elaboración de productos de plástico (15 por ciento) y fabricación de tejidos y prendas de vestir ( 7 por ciento).
El resto de la inversión coreana se concentra en el sector comercio, específicamente en la comercialización de productos alimenticios y alimentos para animales. Entre las 100 principales maquiladoras de México, destacan tres coreanas: Samsung en electrónicos (que con dos plantas emplea a 5789 trabajadores); Daewoo también en la rama de electrónicos (con tres plantas y un nivel de empleo de 4856

Cuadro 8

Inversión extranjera directa de la Cuenca del Pacífico en México*

(miles de dólares)

\begin{tabular}{|c|c|c|c|c|c|c|c|}
\hline Países & 1999 & 2000 & 2001 & 2002 & 2003 & $\begin{array}{l}\text { Acumulado } \\
1999-2003^{1 /}\end{array}$ & $\begin{array}{l}\text { Part. } \\
\% \\
\end{array}$ \\
\hline IED Total & $13,205,506.7$ & $16,585,705.6$ & $26,775,686.3$ & $13,628,161.0$ & $9,738,458.1$ & $79,933,517.7$ & \\
\hline Cuenca del Pacífico & $1,376,831.5$ & $561,488.5$ & $571,771.0$ & $283,066.7$ & $181,909.8$ & $2,975,067.5$ & 100.0 \\
\hline Japón & $1,232,630.7$ & $416,800.1$ & $178,281.1$ & $149,713.5$ & $97,677.5$ & $2,075,102.8$ & 69.7 \\
\hline Singapur & $66,065.5$ & $80,949.4$ & $320,898.9$ & $49,691.5$ & $14,262.6$ & $531,868.0$ & 17.9 \\
\hline Corea & $46,179.9$ & $29,763.0$ & $43,859.6$ & $30,614.0$ & $39,516.1$ & $189,932.5$ & 6.4 \\
\hline Taiwan & $19,831.7$ & $11,493.9$ & $21,545.3$ & $13,874.5$ & $18,324.4$ & $85,069.8$ & 2.9 \\
\hline Nueva Zelanda & 38.5 & 24.9 & $1,655.4$ & $43,124.8$ & 52.5 & $44,896.1$ & 1.5 \\
\hline China & $4,984.2$ & $10,770.6$ & $2,257.3$ & $-2,451.5$ & $5,655.3$ & $21,215.9$ & 0.7 \\
\hline Australia & $7,909.0$ & $7,470.3$ & $4,292.0$ & $-2,097.2$ & $4,219.9$ & $21,794.0$ & 0.7 \\
\hline Hong Kong & $2,379.8$ & $4,009.1$ & $-1,048.6$ & -109.6 & $2,113.9$ & $7,344.6$ & 0.2 \\
\hline Malaisia & 5.3 & 84.4 & 13.0 & 426.3 & 6.7 & 535.6 & 0.0 \\
\hline Indonesia & 0.0 & 0.0 & 0.0 & 275.0 & 0.0 & 275.0 & 0.0 \\
\hline Tailandia & 25.1 & 9.6 & -77.6 & 0.0 & 80.9 & 38.0 & 0.0 \\
\hline Filipinas & $-3,218.0$ & 113.2 & 94.5 & 5.3 & 0.0 & $-3,004.9$ & -0.1 \\
\hline Resto países & $11,828,675.2$ & $16,024,217.1$ & $26,203,915.3$ & $13,345,094.3$ & $9,556,548.3$ & $76,958,450.2$ & \\
\hline \multicolumn{8}{|c|}{ Estructura por países (porcentaies) } \\
\hline IED Total & 100.0 & 100.0 & 100.0 & 100.0 & 100.0 & 100.0 & \\
\hline Cuenca del Pacífico & 10.4 & 3.4 & 2.1 & 2.1 & 1.9 & 3.7 & \\
\hline Japón & 9.3 & 2.5 & 0.7 & 1.1 & 1.0 & 2.6 & \\
\hline Singapur & 0.5 & 0.5 & 1.2 & 0.4 & 0.1 & 0.7 & \\
\hline Corea & 0.3 & 0.2 & 0.2 & 0.2 & 0.4 & 0.2 & \\
\hline Taiwan & 0.2 & 0.1 & 0.1 & 0.1 & 0.2 & 0.1 & \\
\hline Nueva Zelanda & 0.0 & 0.0 & 0.0 & 0.3 & 0.0 & 0.1 & \\
\hline China & 0.0 & 0.1 & 0.0 & 0.0 & 0.1 & 0.0 & \\
\hline Australia & 0.1 & 0.0 & 0.0 & 0.0 & 0.0 & 0.0 & \\
\hline Hong Kong & 0.0 & 0.0 & 0.0 & 0.0 & 0.0 & 0.0 & \\
\hline Malaisia & 0.0 & 0.0 & 0.0 & 0.0 & 0.0 & 0.0 & \\
\hline Indonesia & 0.0 & 0.0 & 0.0 & 0.0 & 0.0 & 0.0 & \\
\hline Tailandia & 0.0 & 0.0 & 0.0 & 0.0 & 0.0 & 0.0 & \\
\hline Filipinas & 0.0 & 0.0 & 0.0 & 0.0 & 0.0 & 0.0 & \\
\hline Resto países & 89.6 & 96.6 & 97.9 & 97.9 & 98.1 & 96.3 & \\
\hline
\end{tabular}

*/ La inversión extranjera directa se integra con los conceptos de nuevas inversiones, reinversión de utilidades y cuentas entre compañías, que se han notificado al RNIE, más las importaciones de activo fijo realizadas por sociedades maquiladoras.

Cabe mencionar que esta información no reporta toda la inversión realizada por inversionistas de la Cuenca del Pacífico, debido a que no se incluyen las inversiones que realizan las empresas de esa región a través de sus filiales en otros países, pues el país de la inversión se clasifica con base en la nacionalidad del inversionista extranjero y no respecto del origen primario de los recursos.

1/ Notificada al 31 de marzo de 2003.

Fuente: Secretaría de Economía. Dirección General de Inversión Extranjera. Consultar en: www.economía-snci-gob.mx. 
trabajadores) y Hyundai Motor Company (con una planta y 2625 empleados). Tanto Samsung como LG han participado en las exportaciones mexicanas de televisores a Estados Unidos aprovechando las ventajas que brinda el TLCAN.

Corea es actualmente un importante inversionista en el exterior. De 1994 a 2003, el promedio de la IED coreana en el extranjero fue de 3.7 mil millones de dólares anuales. De ese monto, únicamente 1.68 por ciento (64 millones anuales en promedio) se destinó a México. Corea ofrece así también oportunidades para incrementar los flujos de inversión hacia México y simultáneamente aprovechar el avance tecnológico de ese país para fortalecer el sector exportador mexicano. Corea desarrolló su sector exportador en buena medida con inversión japonesa orientada al comercio exterior.

\section{Cooperación en educación e intercambio académico}

En el área educativa, también se han realizado acciones importantes para vincular los dos países. En este caso, la Universidad de Guadalajara ha contribuido a estrechar relaciones con instituciones académicas en Corea. Cabe mencionar los casos de la Universidad de Kyung Hee y la Universidad Nacional de Seúl, ambas instituciones académicas de primera en Corea. Con la Universidad de Kyung Hee la relación inició en 1993 y actualmente se lleva a cabo un proyecto conjunto de investigación que constituye un estudio comparativo sobre el impacto de la globalización en el desarrollo económico, político y social de los dos países.

En 1999 la Universidad de Guadalajara firmó un convenio con la Universidad Nacional de Seúl (UNS) para el intercambio de profesores y estudiantes. Los departamentos de Letras (del Centro Universitario de Ciencias Sociales y Humanidades, CUcSH, de la UdeG) y el de Lingüística y Literatura Española de la uns son los que han continuado participando activamente en el intercambio académico entre las dos universidades, con el objetivo de la enseñanza de la lengua española y la difusión de la cultura mexicana. Entre 1999 y 2004, 30 estudiantes de la uns han realizado estancias de intercambio en el cucsH. Por parte del cucsH y en el mismo período, seis profesores han realizado estancias en la uns y dos estudiantes hicieron estancias de intercambio. Otras universidades coreanas, como la Sun Moon, también envían estudiantes a la Universidad de Guadalajara para el aprendizaje del español y la cultura mexicana.

\section{Conclusión}

Aunque la relación bilateral entre Corea y México se ha estrechado a partir de los noventa, ésta ofrece un amplio potencial de profundización no sólo en las áreas de comercio e inversión, sino también en la cooperación técnica, agrícola y, por supuesto, en el intercambio cultural. Hasta ahora ese potencial no ha sido aprovechado ampliamente.

\section{Notas}

1 Las cifras presentadas en esta sección provienen de Falck Reyes, Melba, La economía política de la política agrícola en Asia del Este: Japón, Corea del Sur y Taiwán, Tesis doctoral inédita, Universidad de Colima, agosto 2003.

2 Idem.

3 Véase, Franck, Penelope, and Boestel, Johanna and Choo Yyop Kim,Agriculture and Economic Development in East Asia. From Growth to protectionism in Japan, Kore and Taiwan, Ed. Routledge, London, 1999, p. 37.

4 Bureau of Labor Statistics, Foreign Labor Statistics, U.S. Department of Labor, http://www.bls.gov/fls en general y en particular ftp://ftp.bls.gov/pub/ special.requests/ForeignLabor/ind2000.txt.

5 Idem.

6 OECD, Regulatory Reform in Korea, OECD, Francia, 2000.

7 Castells, Manuel, “¿Hacia la era del Pacífico? El fundamento multicultural de la interdependencia económica" en La era de la Información. Economía, Sociedady Cultura. Fin de Milenio, III, Ed. Siglo XXI, 1999, p. 284.

8 De acuerdo con el Banco Mundial, World Bank, World Development Indicators 03, 2003, utilizando el ingreso nacional bruto para el 2001 para establecer elranking.

9 Véase Becker, Guillermo, México ¿̇tiene salida?, Fondo de Cultura Económica, México, 1999, p. 101, cuadro IV.20. En este libro el autor señala que en 1950 el ingreso per cápita en dólares para México era de 1169 y el de Corea de 564, o sea aproximadamente la mitad del de los mexicanos.

11 Para Corea la cifras provienen de National Statistical Office, Korea Statistical Yearbook 1999, Republic of 
Korea y para México, Banco de México, Informe Anual 2001, Apéndice Estadístico, México.

12 Nam-Kwon Mun y Quintana Romero, Luis, "El comercio de México con Corea del Sur en el marco del TLCAN" en Comercio Exterior, vol. 53, núm. 12, diciembre de 2003, p. 1148.

13 Ministerio de Relaciones Exteriores y Comercio de Corea, http://www.mofat.go.kr/en/rel/e_rel_view.mof

14 Nam-Kwon Mun, op. cit., p. 1150.

15 Las cifras correspondientes a las exportaciones se han tomado de fuentes coreanas, ya que hay exportaciones que México hace a Corea vía Estados Unidos, y por lo tanto México en sus estadísticas las reporta como exportaciones a Estados Unidos. En consecuencia, la estadística mexicana tiende a subestimar el monto de exportaciones.

16 Nam-Kwon Mun y Quintana Romero, Luis, "El comercio de México con Corea del Sur en el marco del TLCAN" en Comercio Exterior, vol. 53, núm. 12, diciembre de 2003, p. 1148.

17 La inversión coreana también ha aumentado en México. Actualmente hay 768 empresas con inversión coreana en el país, casi el doble del número de empresas japonesas. Del total de empresas con inversión japonesa, 33 por ciento están en la industria manufacturera y 60 por ciento se ubican en el comercio. De la región de la Cuenca del Pacífico, Corea ocupa el tercer lugar, antecedido por Japón y Singapur, como país inversor, con una participación de 5.3 por ciento del monto total de inversión acumulado entre 1999 y 2002. Cifras de la Secretaría de Economía, Dirección General de Inversión Extranjera.

18 oECD, Review of Agricultural Policies in Korea, OECD, Francia, 1999, p. 39.

19 Cifras provenientes de Falck Reyes, Melba, La economía política de la política agrícola en Asia del Este: Japón, Corea del Sur y Taiwán, Tesis doctoral inédita, Universidad de Colima, agosto, 2003.

20 Los principales productos agroalimentarios que exporta Corea son carne de cerdo, manzanas, kimchi, tallarines instantáneos y productos de ginseng. Estos productos representaron alrededor de 5 por ciento del valor de la producción agrícola. El mercado más importante para Corea es Japón.

21 Es importante remarcar que estas cifras de la IED coreana en México no incluyen las que hacen filiales coreanas establecidas en otros países, ya que el país de la inversión se clasifica con base en la nacionalidad del inversionista y no respecto del origen primario de los recursos. $m:$ 